For personal use only. Not to be reproduced without permission of the publisher (editorial@gabi-journal.net).

\title{
Patent expiry dates for best-selling biologicals
}

Biosimilars have been approved in Europe since 2006. With patents on originator biologicals expiring and ever-tightening healthcare budgets biosimilars are likely to take an increasing share of the biologicals market. In light of these facts, this article gives estimated patent expiry dates for just some of the best-selling biologicals.

Keywords: Biological, biosimilar, patent

Biosimilars are now a reality. The European Medicines Agency (EMA) approved its first biosimilar Omnitrope (somatropin) back in 2006 [1]. Since then, EMA has approved more than 20 biosimilars within the product classes of human growth hormone, granulocyte colony-stimulating factor, erythtropoesis stimulating agent, insulin and tumour necrosis factor (TNF)-inhibitor, for use in the European Union (EU).

Many blockbuster biologicals have already or will soon face competition from biosimilars due to patent expiries and loss of exclusivity. There are also more than 200 new biotechnology

\section{Figure 1: Patent expiry dates on best-selling biologicals}

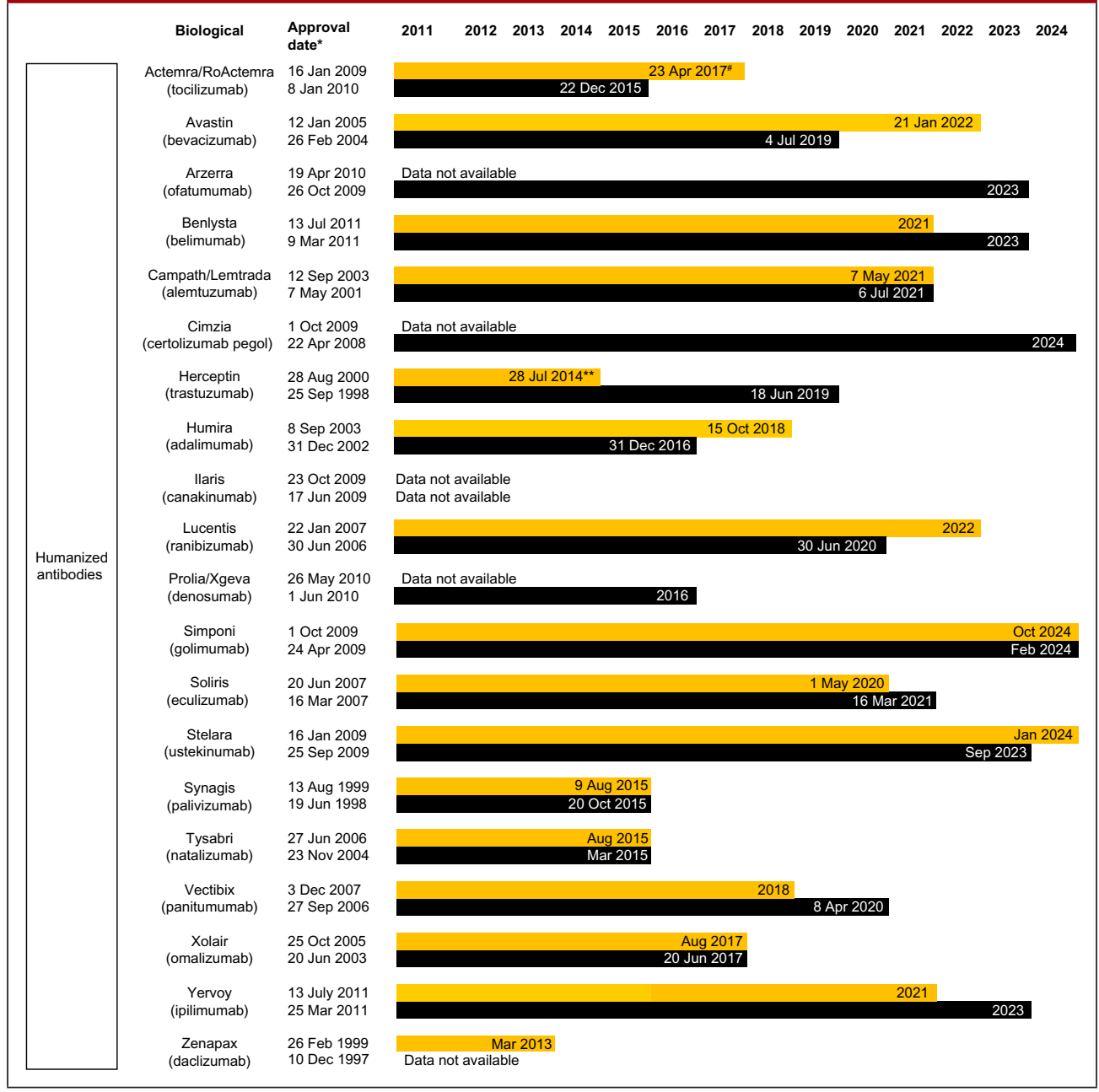

(Continued)

products in the pipeline (phase II to registered), all of which could be future targets for biosimilars. With the increasing price of new biologicals and continuing pressure on healthcare budgets, biosimilars are expected to make up an increasing share of the biologicals market.

There has been significant harmonization across the globe with respect to patents, mainly as a result of the World Trade Organization's TRIPS agreement (Agreement on Trade-Related Aspects of Intellectual Property Rights). This has resulted in most patent laws nowadays, giving the term of a patent as 20 years from the filing date of the application.

The European Patent Convention requires all jurisdictions to give a European patent a term of 20 years from the actual date of filing an application for a European patent or the actual date of filing an international application under the Patent Cooperation Treaty (PCT) designating the European Patent Office.

In the US, for utility patents filed on or after 8 June 1995 , the term of the patent is 20 years from the earliest filing date of the application on which the patent was granted and any prior US or PCT applications from which the patent claims priority. For patents filed prior to 8 June 1995 , the term of patent is either 20 years from the earliest filing date as above (excluding provisional applications) or 17 years from the issue date, whichever is longer.

For both Europe and the US exclusivity periods should also be considered.

Estimated patent and exclusivity period expiry dates for just some of the best-selling biological molecules are shown in Figure 1.

Although the EU previously defined a period of 10 years data exclusivity, 


\section{Figure 1: Patent expiry dates on best-selling biologicals (Continued)}

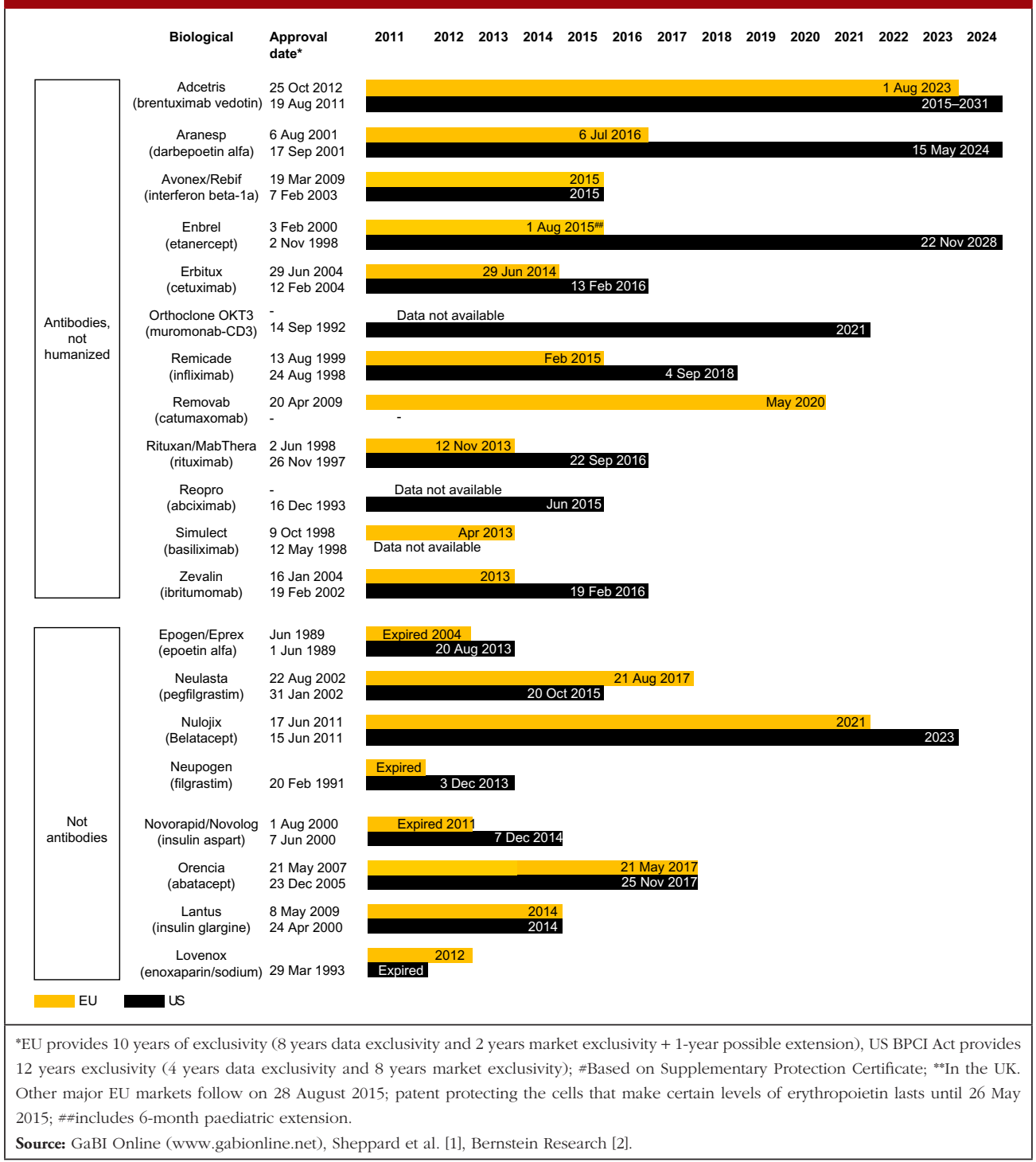

for biosimilars to enter the market and increase industry competition. Price reduction strategies should increase adoption among physicians and patients alike, spurring increases in the biosimilars market share.

According to a report by Frost and Sullivan the global market for biosimilars will rapidly expand more than 20-fold from 2013 to 2019. The biosimilars market is expected to increase from just US\$1.2 billion during 2013 to US $\$ 23$ billion in 2019. Demand is being fuelled by governments around the world turning to biosimilars as a cheaper option to reduce healthcare costs. Government initiatives, strategic collaborations and increasing incidents of new diseases are also increasing the value of the market. Deeper penetration into the markets in Europe, Japan and the US, as well as emerging economies in Asia and Latin America is also helping to increase the biosimilars market share.

Major companies investing in the biosimilars market include Amgen, Biocon, Biopartners, Hospira, Intas Biopharmaceultical, Mylan, Dr Reddy's Laboratories, Sandoz and Teva.

\section{Competing interests: None.}

Provenance and peer review: Article prepared based on extensive this was revised at the latest review of pharmaceutical EU legislation to the following:

Ten years if the reference product is centrally approved or application to the centralized procedure has been made before 20 November 2005. Or eight years data exclusivity +2 years market exclusivity +1 year possible extension if a full dossier is submitted on or after 30 October 2005 via a national procedure or after 20 November 2005 via the centralized procedure [3].

The expiration of patents and other intellectual property rights for originator biologicals over the next decade opens up opportunities research; internally peer reviewed.

Michelle Derbyshire, PhD, GaBI Online Editor

\section{Reference}

1. GaBI Online - Generics and Biosimilars Initiative. Biosimilars approved in Europe [www.gabionline.net]. Mol, Belgium: Pro Pharma Communications International; [cited 2015 Nov 19]. Available from: www.gabionline.net/ Biosimilars/General/Biosimilars-approved-in-Europe DOI: 10.5639/gabij.2015.0404.040

Copyright (C) 2015 Pro Pharma Communications International 